\title{
Changing trends in blood transfusion in children and neonates admitted in Kilifi District Hospital, Kenya
}

\author{
Rosalon Pedro ${ }^{1,2}$, Samuel Akech', Kathryn Maitland ${ }^{1,3^{*}}$
}

\begin{abstract}
Background: Severe anaemia is a common cause for hospitalization in children in sub-Saharan Africa. Malaria plays an important aetiological role, resulting in a substantial burden of paediatric transfusion in hospitals. A decline in malaria and paediatric admissions to the Kilifi District Hospital has been reported recently. This study aimed to investigate whether this trend affected clinical burden, clinical severity of anaemia and requirements for paediatric transfusion.

Methods: Eight-year retrospective review of paediatric admissions to Kilifi District Hospital, Kenya describing the frequency of moderate and severe anaemia, blood transfusion and case fatality over time. Definitions for severe anaemia were $\mathrm{Hb}<8 \mathrm{~g} / \mathrm{dl}$ for newborns and $<5 \mathrm{~g} / \mathrm{dl}$ for other age groups and for moderate anaemia was $\mathrm{Hb} 8$ to $<11 \mathrm{~g} / \mathrm{dl}$ for newborns and 5 to $<9.3 \mathrm{~g} / \mathrm{dl}$ for other age groups. Life threatening anaemia was defined as severe anaemia $(\mathrm{Hb}<5 \mathrm{~g} / \mathrm{dl}$ ) complicated by either deep breathing or prostration or profound anaemia $(\mathrm{Hb}<4 \mathrm{~g} / \mathrm{dl}$ ) alone.

Results: Of the 35,139 admissions 13,037 (37\%) had moderate anaemia and 2,265 (6\%) had severe anaemia; respiratory distress complicated $35 \%$ of cases with $\mathrm{Hb}<5 \mathrm{~g} / \mathrm{dl}$. Concurrent with the decline in malaria there was a marked decline in the prevalence of severe anaemia between $2002(8 \%)$ and $2009(<4 \%)$ (chi ${ }^{2}$ for trend $=134$, $P<0.0001$ ). The number and proportion of admissions transfused also declined significantly over this time (chi2 for trend $=152, \mathrm{P}<0.0001$ ). Of the 2,265 children with severe anaemia 191 (8\%) died. Case fatality remained unchanged during this period $(P<0.26)$ and was largely explained by the unchanged proportion with lifethreatening anaemia, present in $58-65 \%$ of cases throughout the study period.

Conclusion: The impact of reduced malaria transmission on child morbidity has positive public benefits on the demand and use of blood for paediatric transfusion. Despite an overall reduction in paediatric transfusion requirement, case fatality of severe anaemia remained unchanged over this decade. Further research is required to improve outcome from severe anaemia, particularly in the high-risk group with life threatening features.
\end{abstract}

\section{Background}

In sub-Saharan Africa severe anaemia is a leading cause of paediatric admission to hospital. The community prevalence of anaemia in African children, defined as a haemoglobin $(\mathrm{Hb})<11 \mathrm{~g} / \mathrm{dl}$, ranges from $49 \%$ to $89 \%$ and severe anaemia (variously defined as $\mathrm{Hb}<5 \mathrm{~g} / \mathrm{dl},<6 \mathrm{~g} / \mathrm{dl}$ or $\mathrm{Hb}<7 \mathrm{~g} / \mathrm{dl}$ ) affects between $1 \%$ - $6 \%$ of children, with infants being the most vulnerable age group [1]. In hospitalized children the prevalence of severe anaemia

\footnotetext{
* Correspondence: kathryn.maitland@gmail.com

'Kenya Medical Research Institute-Wellcome Trust Programme, PO Box 230, Kilifi, Kenya Full list of author information is available at the end of the article
}

ranges from $8-29 \%[2,3]$, resulting in a high demand for blood transfusion, thus in malaria-endemic Africa paediatric transfusion accounts for up to $70 \%$ of all transfusions prescribed [4].

The aetiology of anaemia is frequently multifactorial [5], commonly associated with Plasmodium falciparum malaria infection [6] and nutritional factors in children admitted to hospital $[2,7]$. The relative risk of in-hospital mortality for children with severe anaemia is almost twice that of their less anaemic counterparts [2]. Despite the provision of blood transfusion, the case fatality of children with severe anaemia remains high. Over $50 \%$ of deaths occurring within hours of admission with a number
C Biomed Central 
occurring in children awaiting urgent transfusion $[7,8]$. Blood transfusion is the definitive and life-saving treatment for acute severe anaemia, resulting in substantial benefit in children with profound anaemia $(\mathrm{Hb}<4 \mathrm{~g} / \mathrm{dl})$ and children with $\mathrm{Hb}$ 4-6 g/dl with severe complications (prostration or deep breathing) [8,9]. However, the majority of transfusions are received by children with severe anaemia (Hb 4-6 g/dl) without life-threatening signs for whom the benefits of urgent transfusion are unproven [10-12]. WHO recommends avoidance of blood transfusion in this group to protect supplies of blood and reduce the risk of adverse reactions and transfusion transmitted infections [4]. Post-discharge morbidity and mortality are important considerations in this group but there are few data on the cumulative incidence of poor outcomes over the longer-term [13].

Despite these guidelines being in place for many years in Africa, up to $50 \%$ of hospitalized children in malaria endemic receive a blood transfusion [13]. Malaria still plays an important role in the onset of severe anaemia, placing a limitation on the ability to reduce the need for paediatric transfusion in hospitals in malaria endemic areas. In Kilifi District Hospital (KDH), Kenya's coast, the policy of restrictive blood transfusion practice has been applied since the late 1990's. English et al evaluated the practice between 1998 and 2000 and found that $13 \%$ of all paediatric admissions (excluding newborns) were transfused [8]. Malaria and severe malnutrition were the main primary diagnoses. In recent years, a decline in malaria and paediatric admissions to the hospital has been reported [14]. This review aimed to investigate whether this trend also affected transfusion practice and requirements for paediatric and neonatal transfusion.

\section{Methods}

A retrospective study of hospital admissions to address the following specific objectives. First, to describe the proportions of anaemia and blood transfusions secondary to malaria and describe the changes over time. Secondly, to examine compliance with the threshold for blood transfusion, established by the World Health Organization (WHO) current transfusion guidelines, and finally, to determine in-hospital survival. Retrospective data review of the clinical surveillance database covering all child and neonatal admissions to Kilifi District Hospital (KDH), Kenya, over an 8-year period, from January 2002 to December 2009. Clinical data are routinely collected prospectively at admission and directly entered into a Filemaker $\operatorname{Pro}^{\circ}$ database, which is password-protected and has limited access. Data on the following were retrieved; age, sex, diagnosis, falciparum malaria parasitaemia, haemoglobin $(\mathrm{Hb})$ level, respiratory distress, level of consciousness, nutritional status, capillary refill $>2$ seconds (as a sign of hypovolvaemic shock) together with data on blood transfusion, length of stay and mortality as outcome variables.

Kilifi District is one of the poorest area in Kenya, where malaria is endemic, with $40 \%$ of children under five years presenting anthropometric measures of malnutrition, half with biochemical markers of iron deficiency, $14 \%$ of children have a sickle cell trait and nearly $60 \%$ have $\alpha+$ thalassaemia deletion genotypes [11].

\section{Analysis}

Proportions of transfusions due to malaria and other diagnoses were calculated for each year and the proportions compared over time. Since transfusion thresholds are different for neonates, we analysed the trends in neonates separately from those of older children. Children outside the neonatal period ( $\geq 1$ month) were further sub-grouped into infants (1-12 months), 1-4 years, and older then 5 years since the prevalence of severe malaria anaemia varies considerably over these age groups. The children were further categorised by their clinical severity features.

Severe anaemia was defined as $\mathrm{Hb}<8 \mathrm{~g} / \mathrm{dl}$ for neonates and $<5 \mathrm{~g} / \mathrm{dl}$ for other age groups; profound anaemia in non-neonatal groups was defined as $\mathrm{Hb}<4 \mathrm{~g} / \mathrm{dl}$. As defined by WHO criteria for anaemia: moderate anaemia was a $\mathrm{Hb} 8-<11 \mathrm{~g} / \mathrm{dl}$ for newborns and $5-<9.3 \mathrm{~g} / \mathrm{dl}$ for other age groups; .mild or no anaemia as $\mathrm{Hb}>11 \mathrm{~g} / \mathrm{dl}$ for newborns and $>9.3 \mathrm{~g} / \mathrm{dl}$ for other age groups. Respiratory distress was defined as either the presence of deep breathing (a clinical feature of metabolic acidosis) or indrawing. Nutritional status was measured by the parameter birth weight or gestational age for neonates (severe malnutrition was equivalent to prematurity or small for gestational age). For the other age groups severe malnutrition was defined as either mid upper arm circumference (MUAC) $<11 \mathrm{~cm}$ and/or presence of oedema (kwashiorkor). Impaired consciousness indicated the presence of prostration (inability to sit unsupported if $>9$ months or inability to breast feed if $\leq 9$ months). Lifethreatening anaemia was defined as either profound anaemia $(\mathrm{Hb}<4 \mathrm{~g} / \mathrm{dl})$ irrespective of clinical severity or severe anaemia $(\mathrm{Hb}<5 \mathrm{~g} / \mathrm{dl})$ complicated by deep breathing or prostration. Stata version 11 (Stata corporation, Texas, United States) was used for data analysis for descriptive statistics.

\section{Results}

Over the eight year period 36,621 children $<13$ years were admitted. Admission haemoglobin $(\mathrm{Hb})$ was available for 35,139 and missing in 1482 (3.9\%). Moderate anaemia occured in 13,037 (37\%) and 2,265 (6\%) had severe anaemia (Table 1). Severe anaemia was commonest in children 1-12 years (8\%) and less prevalent in newborns, with only 91 (2\%) cases being affected. Respiratory 
Table 1 Main clinical characteristics of admissions by age group

\begin{tabular}{|c|c|c|c|c|c|}
\hline \multirow[t]{2}{*}{ FEATURES } & \multicolumn{5}{|c|}{ Age Groups } \\
\hline & Neonates & Infant & Children $1-4$ years & Children $5-13$ years & Total \\
\hline $\mathrm{N}(\%)$ & $5114(14)$ & $10167(28)$ & $16395(45)$ & $4945(14)$ & 36621 \\
\hline Age median & 3 days & 6.5 months & 2 years & 7.5 years & 1.4 years \\
\hline Male n (\%) & $2987(58)$ & $5787(57)$ & $9122(56)$ & $2744(55)$ & $20640(56)$ \\
\hline Malaria parasitemia (\%) & $18(0.4)$ & $1284(13)$ & $5512(35)$ & $1224(26)$ & $8038(23)$ \\
\hline Transfused (\%) & $347(7)$ & $642(7)$ & $1338(9)$ & $395(8)$ & $2722(8)$ \\
\hline Not transfused (\%) & $4570(93)$ & $9073(93)$ & $14307(91)$ & $4335(92)$ & $32285(92)$ \\
\hline Transfusion Missing value & 197 & 452 & 750 & 215 & 1614 \\
\hline Mild or without anaemia (\%) & 4335 (91) & $5127(53)$ & $7378(47)$ & $2997(63)$ & $19837(56)$ \\
\hline Moderate anaemia (\%) & $359(8)$ & $4087(42)$ & $7177(45)$ & $1414(30)$ & $13037(37)$ \\
\hline Severe anaemia (\%) & $91(2)$ & $526(5)$ & $1279(8)$ & $369(8)$ & $2265(6)$ \\
\hline Haemoglobin value missing & 329 & 427 & 561 & 165 & 1482 \\
\hline Severe anaemia + Respiratory distress (\%) & $38(42)$ & $261(50)$ & $413(32)$ & $72(20)$ & $784(35)$ \\
\hline Severe anaemia case fatality (\%) & $28(31)$ & $35(7)$ & $91(7)$ & $37(10)$ & $191(8)$ \\
\hline
\end{tabular}

distress complicated $35 \%$ of cases with $\mathrm{Hb}<5 \mathrm{~g} / \mathrm{dl}$, and was more prevalent in infants and newborn. Concomitant malaria parasitaemia, rarely present in neonates, was common in all other age groups but its prevalence was more closely tied to the year of study than age. Over the study period there was a significant decline in malaria across all ages groups (Figure 1$)\left(\mathrm{chi}^{2}\right.$ test for trend $=$ $2440, \mathrm{P}<0.0001$ ), which is covered in more detail in a previous report [14]. Primary and secondary diagnoses were recorded by clinicians at discharge. The most common discharge diagnoses were anaemia (76\%),
P. falciparum malaria (46\%) and all types of malnutrition with $13 \%$ (Table 2).

Concurrent with the decline in malaria there was a marked decline in the prevalence of severe anaemia (Figure 2) from 2002 to 2009 ( $\mathrm{chi}^{2}$ for trend $=134, \mathrm{P}<$ 0.0001 ). Overall, $8 \%$ of admissions in 2002 had severe anaemia which decreased to $<4 \%$ by 2009 . The effect was the most dramatic in infants and young children where proportions with severe anaemia declined from $10 \%$ of admissions to $2 \%$. A steep decline was present in most age groups except children 5-12 years who showed

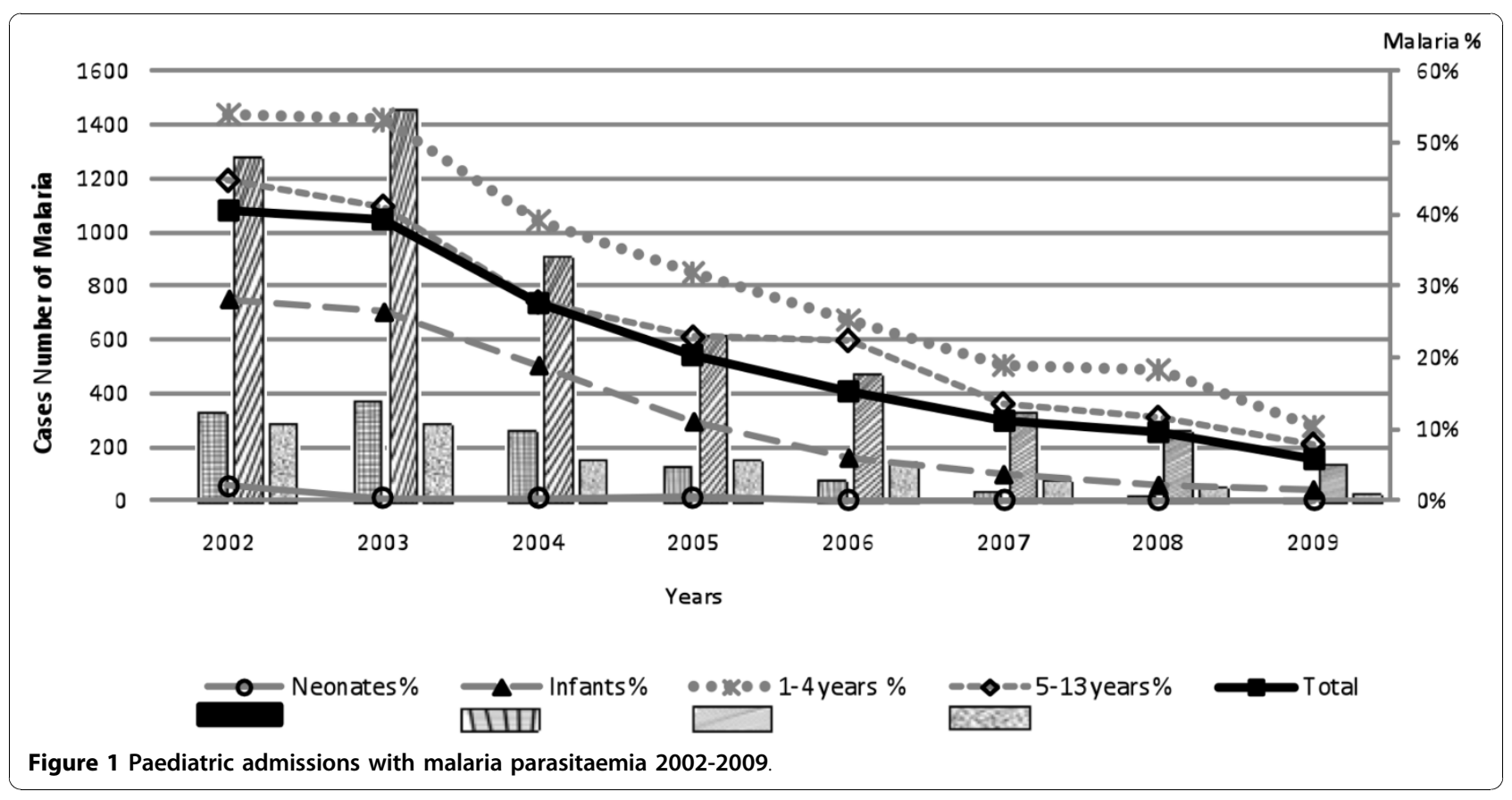


Table 2 Clinicians primary and secondary discharge diagnosis of children with severe anaemia

\begin{tabular}{lccc}
\hline Diagnosis & Primary & Secondary & Total (\%) \\
\hline Anaemia & 760 & 960 & $1720(76)$ \\
\hline Plasmodium falciparum malaria & 730 & 316 & $1046(46)$ \\
\hline Severe malnutrition & 218 & 66 & $284(13)$ \\
\hline Lower respiratory tract infection & 118 & 79 & $197(9)$ \\
\hline Sickle cell disease & 148 & 33 & $181(8)$ \\
\hline Septicaemia/Sepsis & 66 & 55 & $121(5)$ \\
\hline Gastroenteritis & 33 & 23 & $56(2)$ \\
\hline Encephalopathy & 16 & 17 & $33(1)$ \\
\hline Neonatal jaundice & 23 & 10 & $33(1)$ \\
\hline HIV exposed or infected & 19 & 39 & $58(3)$ \\
\hline Other & 124 & 151 & $275(12)$ \\
\hline Not recorded & 10 & & $10(0.4)$ \\
\hline Total & 2265 & 1749 & \\
\hline
\end{tabular}

an initial steep decline in prevalence in the years 20022005, which plateaued then rose again in 2008 .

\section{Transfusion}

Two thousand seven hundred and twenty two children received a transfusion (7.4\%). The majority of transfusions, $55 \%(1,490)$, were received by children with severe anaemia, 29\% (789) were received by children admitted with moderate anaemia ( $\mathrm{Hb} 5.0-9.3 \mathrm{~g} / \mathrm{dl}$ ) and 14\% (375) received by children who had mild or no anaemia $(\mathrm{Hb}$ $>9.3 \mathrm{~g} / \mathrm{dl}$ ) at admission. Two percent of transfusions were given to children whose $\mathrm{Hb}$ values were not recorded on admission. These relative proportions were constant throughout the period of the study. The number and proportion of admissions transfused declined significantly over time $\left(\mathrm{chi}^{2}\right.$ for trend $\left.=152, \mathrm{P}<0.0001\right)$ mirroring the reduction in severe anaemia (Figure 3 ). In the 5-12 year age group, there was an increase in transfusions in 20072009 which was largely accounted for by the increase in severe anaemia.

\section{Clinical severity of anaemia}

Of the 2265 children with severe anaemia 191 (8\%) died. The highest case fatality was in the neonatal group (31\%) (Table 1). There was little difference in mortality in children with severe anaemia who received a transfusion, 9\% (129/1490), and those who were not transfused, 8\% (59/ 737) (Table 3). Admission features of children with severe anaemia were compared in fatal and non-fatal cases (Table 3). Respiratory distress was common 784 (24\%) and associated with an elevated mortality of $15 \%(115 / 784$ patients); children < 1 year being most affected. Deep 'acidotic' breathing had a higher case fatality (20\%) than indrawing (14\%). Prostration was present in $414(20 \%)$ and, of these, 20\% (81/414 patients) died. Shock (defined by capillary refilling time $>2$ seconds) complicated 460 (20\%) cases and 18\% (81/460 patients) died. Severe malnutrition, incorporating both marasmus (or low gestational age for newborns) and kwashiorkor complicated $18 \%$ (413/2,265 patients) of cases of severe anaemia with an overall case fatality of $17 \%(70 / 413)$. Both age and type of

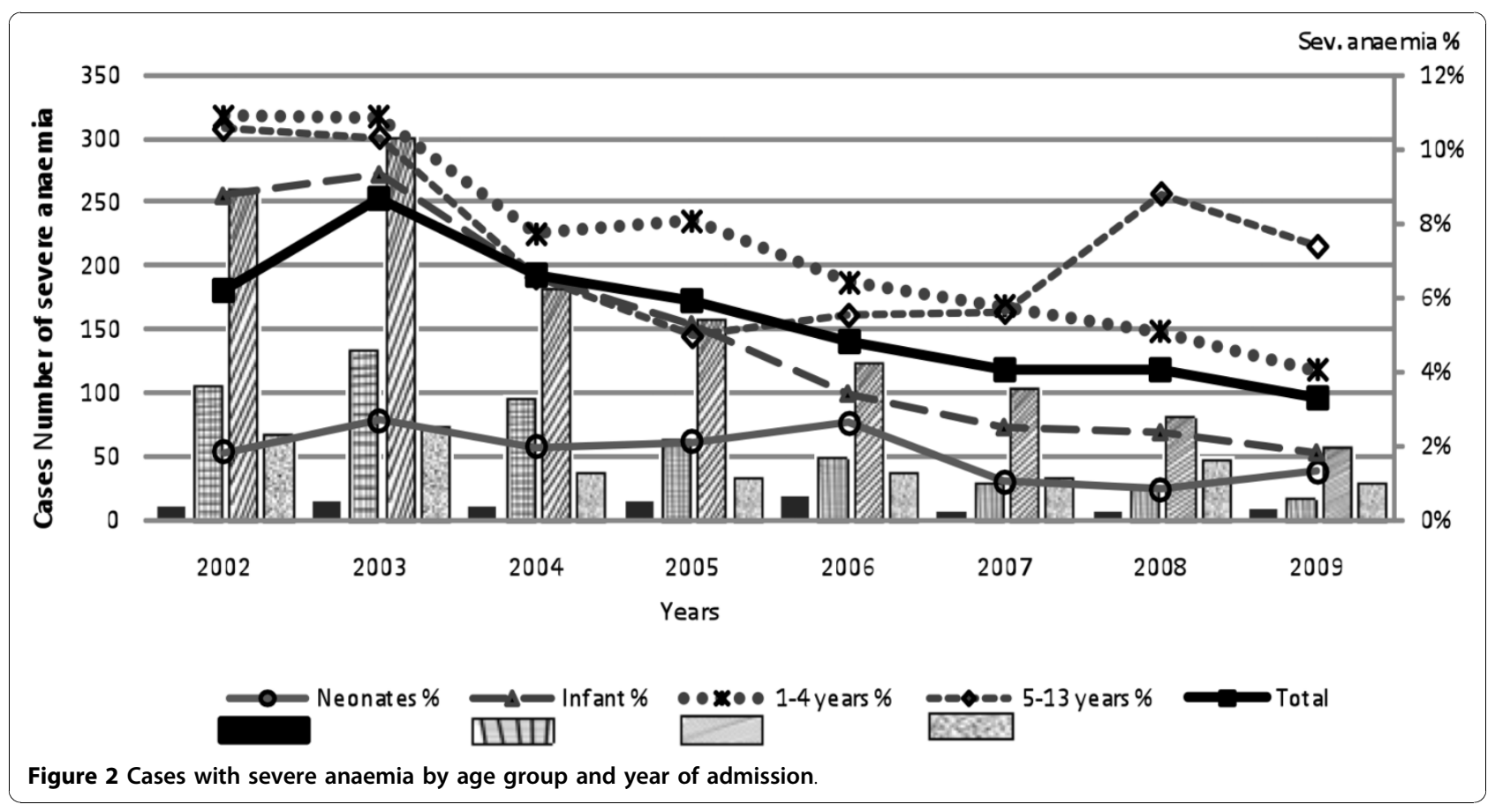




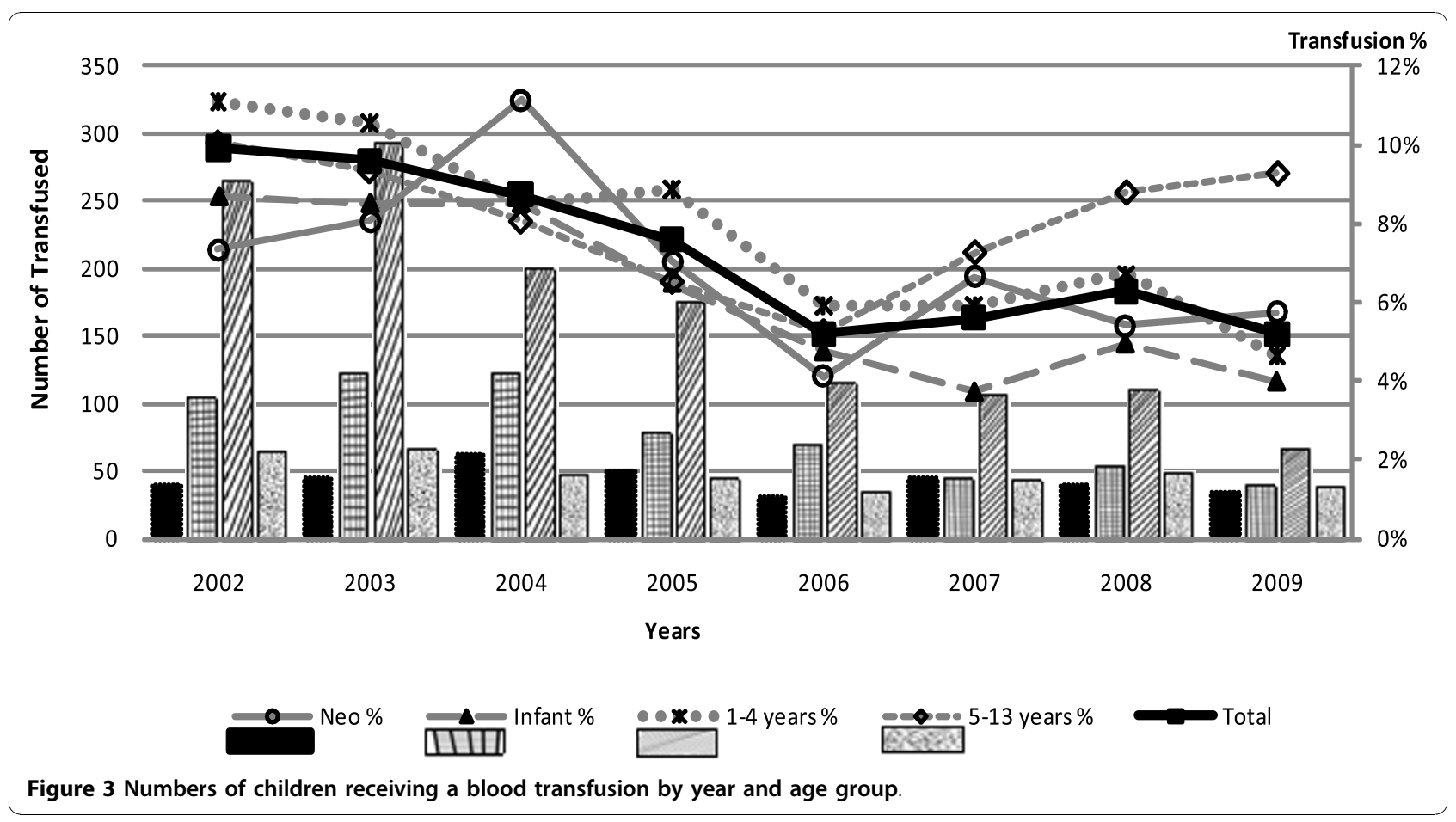

malnutrition (kwashiorkor) affected outcome. Malaria parasitaemia was most common in infants with severe anaemia, 1,113 (49\%), but rare in neonates. Malaria parasitaemia was associated with a lower case fatality 7\% (74/ 1,118 patients) compared children with any other complication or co-morbidity.

\section{Mortality over time}

Data were examined to determine whether the decline in malaria, severe anaemia and requirements for transfusion had any bearing on the case fatality rates of severe anaemia (Figure 2). The absolute number of deaths from severe anaemia declined due to a reduction in case

Table 3 Distribution of severe anaemia and fatality by severity features and age group

\begin{tabular}{|c|c|c|c|c|c|c|c|c|c|c|}
\hline \multirow[b]{2}{*}{ CLINICAL FEATURES } & \multicolumn{2}{|c|}{ Neonates } & \multicolumn{2}{|c|}{ Infants } & \multicolumn{2}{|c|}{ Children 1-4 yrs } & \multicolumn{2}{|c|}{ Children 5-13 yrs } & \multicolumn{2}{|c|}{ Total } \\
\hline & $\begin{array}{c}n \\
(\%)\end{array}$ & CF (\%) & $\begin{array}{c}n \\
(\%)\end{array}$ & CF (\%) & $\begin{array}{c}n \\
(\%)\end{array}$ & $\begin{array}{l}\mathrm{CF} \\
(\%)\end{array}$ & $\begin{array}{c}n \\
(\%)\end{array}$ & $\begin{array}{l}\mathrm{CF} \\
(\%)\end{array}$ & $\begin{array}{c}\mathrm{N} \\
(\%)\end{array}$ & CF (\%) \\
\hline $\mathrm{N}$ & \multicolumn{2}{|c|}{91} & \multicolumn{2}{|c|}{526} & \multicolumn{2}{|c|}{1279} & \multicolumn{2}{|c|}{369} & \multicolumn{2}{|c|}{2265} \\
\hline Age median [IQR] & \multicolumn{2}{|c|}{4 days [2-10] } & \multicolumn{2}{|c|}{8 mths [6-10] } & \multicolumn{2}{|c|}{2 yrs [1.5-3] } & \multicolumn{2}{|c|}{7.5 yrs [6-9.5] } & \multicolumn{2}{|c|}{1.9 yrs [0.9-3.6] } \\
\hline Respiratory Distress & $38(42)$ & $12(32)$ & $261(50)$ & $27(10)$ & $413(32)$ & $59(14)$ & $72(20)$ & $17(24)$ & $784(24)$ & $115(15)$ \\
\hline Deep Breathing & $21(23)$ & $10(48)$ & $118(22)$ & $19(16)$ & $261(20)$ & $47(18)$ & $41(11)$ & $11(27)$ & $441(19)$ & $87(20)$ \\
\hline Indrawing & $31(34)$ & $10(32)$ & $208(40)$ & $20(10)$ & $253(20)$ & $33(13)$ & $52(14)$ & $13(25)$ & $544(24)$ & $76(14)$ \\
\hline Capillary refill $>2 \mathrm{~s}$ & $18(20)$ & $7(39)$ & $108(21)$ & $16(15)$ & $279(22)$ & $39(14)$ & $55(15)$ & $19(35)$ & $460(20)$ & $81(18)$ \\
\hline Severe malnutrition & $36(40)$ & $16(44)$ & $98(19)$ & $10(10)$ & $147(19)$ & $35(14)$ & $32(9)$ & $9(28)$ & $413(18)$ & $70(17)$ \\
\hline Prostration & $16(18)$ & $6(38)$ & $85(16)$ & $18(21)$ & $277(22)$ & $48(17)$ & $36(10)$ & $9(25)$ & $414(18)$ & $81(20)$ \\
\hline Malaria parasites & $2(2)$ & $0(0)$ & $288(55)$ & $16(6)$ & $740(58)$ & $52(7)$ & $83(22)$ & $6(7)$ & $1113(49)$ & $74(7)$ \\
\hline Transfused & $44(48)$ & $13(30)$ & $346(66)$ & $28(8)$ & $842(66)$ & $63(7)$ & $258(70)$ & $25(10)$ & $1490(66)$ & $129(9)$ \\
\hline Not transfused & $47(52)$ & $15(32)$ & $164(31)$ & $6(4)$ & $423(33)$ & $27(6)$ & $103(28)$ & $11(11)$ & 737 (33) & $59(8)$ \\
\hline No transfusion status & 0 & & $16(3)$ & $1(6)$ & $14(1)$ & $1(7)$ & $8(2)$ & $1(13)$ & $38(2)$ & $3(8)$ \\
\hline
\end{tabular}

$\mathrm{CF}=$ Case Fatality.

$\mathrm{IQR}=$ Interquartile range.

Respiratory Distress $=$ Deep Breathing or Indrawing.

Severe malnutrition = mid-upper arm circumference $<11 \mathrm{~cm}$ or kwashiorkor or premature or small for gestational age $<2.5 \mathrm{Kg}$ for neonatal group. 
burden however, case fatality remained unchanged during this period with an overall mortality of $8 \%$ ( $<<$ 0.26 ) (Figure 4). The data were explored to determine whether this could be explained by changes in the proportions with severe life threatening anaemia. Children in the high-risk group (life threatening anaemia) were selected to study trends over time (Table 4). Whilst the absolute number cases of severe anaemia fell sharply over the years the proportion of those at high risk remained unchanged being present in 58-65\% of children with $\mathrm{Hb}<5 \mathrm{~g} / \mathrm{dl}$ (severe anaemia). Also notable was that the proportion of life-threatening cases did not vary with age group - with all post neonatal groups having $>60 \%$ of cases complicated by severity features.

\section{Discussion}

This retrospective study of severe anaemia and transfusion practice has highlighted several important points. A considerable reduction the clinical burden of severe anaemia and requirements for transfusions concurrent with the substantial decline in malaria was noted between 2002 and 2009. Malaria parasitaemia was recorded as the leading cause of anaemia and in the absence of the other complications was associated with a lower mortality than for non-malarial cases of severe anaemia. Severe anaemia complicated by deep breathing, prostration and shock were common and were associated with higher case fatalities. Despite the simultaneous declines in disease burden (malaria and anaemia) and demand on transfusion services we found that this had little effect on the overall case fatality rate of children admitted with severe anaemia, with mortality remaining unchanged at $8 \%$ throughout the study period. This was largely explained by the proportion of children with severe anaemia with life threatening complications, which remained constant over the period of study, affecting over $60 \%$ requiring transfusion.

These data suggest that the impact of reduced malaria transmission on child morbidity are greater than those measured by changes in malaria admissions alone. This is reinforced by Gerritsen and colleagues study in South Africa (Limpopo) which found a significant reduction of malaria from 1998 to 2007 [15]. The dramatic reduction in the numbers with severe anaemia and consequently the impact on the requirements for blood transfusion are important 'value added' or hidden benefits of malaria control. Quantifying the reduction in transfusion requirements from the year 2002, where over $10 \%$ of all children admitted KDH received a blood transfusion $(n=477)$ to the year 2009 when only $4 \%$ received a blood transfusion $(\mathrm{n}=181)$, translated to a 2.6 fold decline. The decrease in blood transfusion requirements, in addition to reducing the risk of transmissible diseases and adverse reactions, has an important health economic impact. Taking an average range of the cost of transfusion per child as between 30-50 U.S. Dollars for voluntary unpaid donors [4], an estimated annual saving of USD 8,880 to 14,800 for this hospital alone.

There are a number of potential explanations why reducing the burden of malaria disease and transfusion requirements did not result in a reduction in case fatality. First, that the proportion with life threatening anaemia

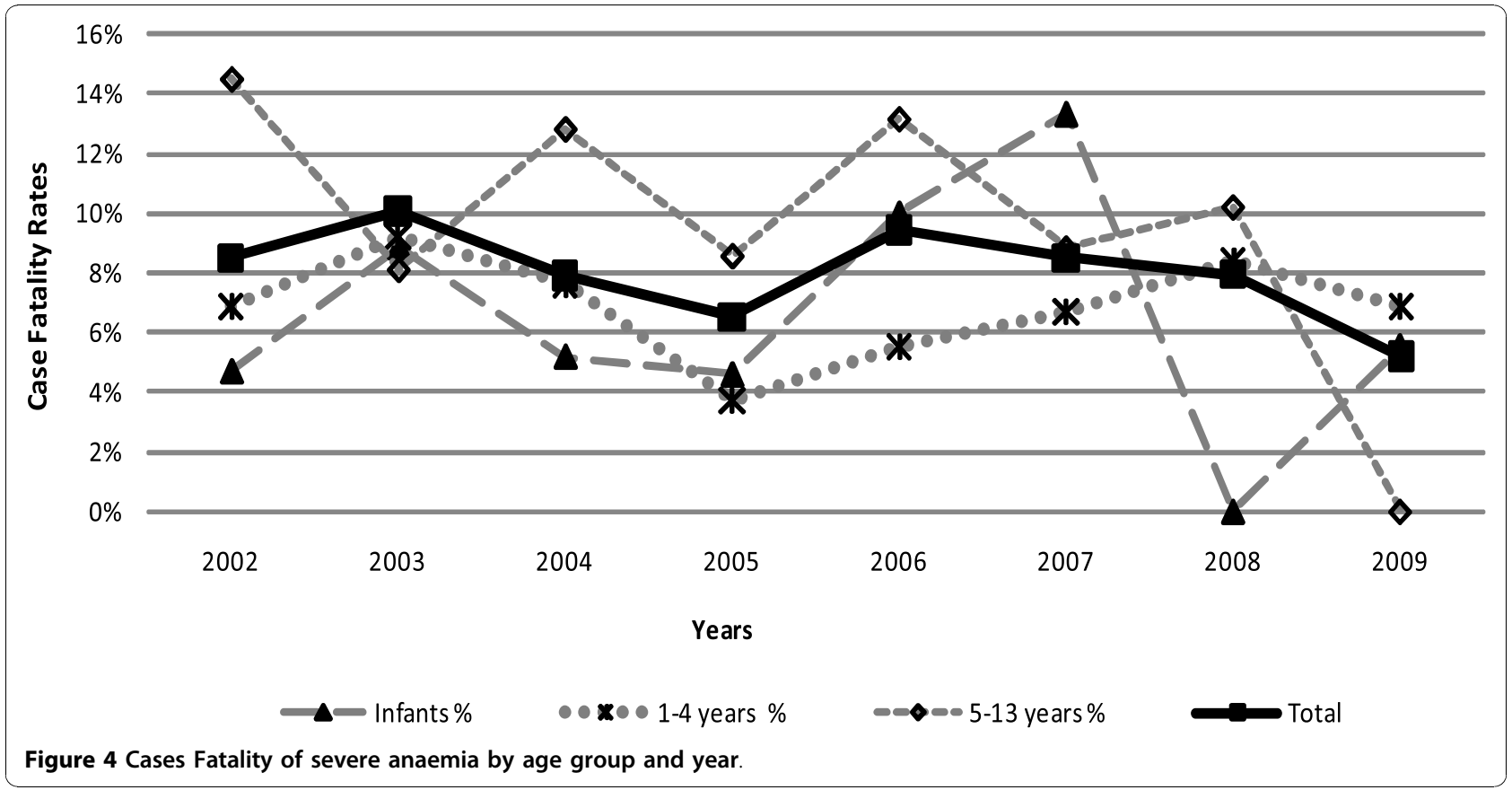


Table 4 Severe anaemia complicated by Deep breathing, Prostration or Profound anaemia

\begin{tabular}{ccccccccccc}
\hline \multirow{2}{*}{ Year } & \multicolumn{2}{c}{ Neonates } & \multicolumn{2}{c}{ Infants } & \multicolumn{2}{c}{ Children 1-4 yrs } & \multicolumn{2}{c}{ Children 5-13 yrs } & Total \\
\cline { 2 - 11 } & $\mathbf{n}$ & D.P.P (\%) & $\mathbf{n}$ & D.P.P(\%) & $\mathbf{n}$ & D.P.P (\%) & $\mathbf{n}$ & D.P.P (\%) & N & D.P.P (\%) \\
\hline $\mathbf{2 0 0 2}$ & 10 & $4(40)$ & 106 & $70(66)$ & 261 & $172(66)$ & 69 & $42(61)$ & 446 & $288(65)$ \\
\hline $\mathbf{2 0 0 3}$ & 15 & $7(47)$ & 135 & $76(56)$ & 303 & $199(66)$ & 74 & $50(68)$ & 527 & $332(63)$ \\
\hline $\mathbf{2 0 0 4}$ & 11 & $4(36)$ & 96 & $63(66)$ & 183 & $121(66)$ & 39 & $27(69)$ & 329 & $215(65)$ \\
\hline $\mathbf{2 0 0 5}$ & 15 & $7(47)$ & 65 & $33(51)$ & 160 & $98(61)$ & 35 & $22(63)$ & 275 & $160(58)$ \\
\hline $\mathbf{2 0 0 6}$ & 19 & $10(53)$ & 50 & $30(60)$ & 126 & $81(64)$ & 38 & $2566)$ & 233 & $146(63)$ \\
\hline $\mathbf{2 0 0 7}$ & 7 & $0(0)$ & 30 & $19(63)$ & 105 & $69(66)$ & 34 & $25(74)$ & 176 & $113(64)$ \\
\hline $\mathbf{2 0 0 8}$ & 6 & $2(33)$ & 26 & $13(50)$ & 83 & $53(64)$ & 49 & $34(69)$ & 164 & $102(62)$ \\
\hline $\mathbf{2 0 0 9}$ & 8 & $3(38)$ & 18 & $12(67)$ & 58 & $40(69)$ & 31 & $20(65)$ & 115 & $75(65)$ \\
\hline Total & 91 & $37(41)$ & 526 & $316(60)$ & 1279 & $833(65)$ & 369 & $245(66)$ & 2265 & $1431(63)$ \\
\hline
\end{tabular}

$\mathbf{n}=$ Number of severe anaemia cases.

D.P.P $=$ Number of cases complicated by deep Breathing or Prostration or Profound anaemia $(\mathrm{Hb}<4 \mathrm{~g} / \mathrm{dl})$.

did not decline and thus the proportion requiring emergency transfusion remained unchanged. Previous work in Kilifi in 2000 by English and colleagues demonstrated that respiratory distress, prostration and profound anaemia, were the clinical features most associated with death, odds ratios of 4.1 (95\% CI $2.2-7.4), 7.4$ (95\% CI 4.2-13.1) and 2.5 (95\% CI 1-4 - 4.5) respectively [8]. This data together with that of others indicate no clear association between receipt of transfusion and in-hospital mortality [16]. However, many of the deaths occur on the day of admission, in children awaiting transfusion. A previous report from Siaya, Kenya indicated that transfusion given after the day of admission had no impact on survival [9]. Currently, $20 \mathrm{ml} / \mathrm{kg}$ of whole blood (or $10 \mathrm{ml} / \mathrm{kg}$ packed cells) is recommended for all levels of anaemia with $\mathrm{Hb}<6 \mathrm{~g} / \mathrm{dl}$ [1]. Few data are available on volume of blood received and indicate only modest rises of mean haemoglobin $2.5-3.3 \mathrm{~g} / \mathrm{dl}[8,9,17]$ and with $25 \%$ of children remaining severely anaemic $(<5 \mathrm{~g} / \mathrm{dL})$ [8] following initial transfusion. Anecdotal evidence from hospitals suggests that multiple, low volume $(20 \mathrm{ml} / \mathrm{kg})$ transfusions are frequently given. Using standard formulae to calculate volume required [18] the current doses prescribed under-treat children with profound anaemia by $\sim 30 \%$. Larger initial transfusion volumes have not been systematically evaluated.

Whilst most groups showed a decline in anaemia and transfusion overtime, there was an increase in children aged 5-12 years in the years 2008-2009. One possible suggestion is that other causes of anaemia were becoming more prominent as a cause of admission in this age group. Unfortunately, in this retrospective study the degree of fine resolution offered by the recorded final diagnosis of severe anaemia does not permit a greater insight into causality.

The effect of introduction of guidelines or protocols that include rationale transfusion practice, restricting blood transfusion use to only those at greatest risk has been examined in several randomized studies in adults, children and newborns. A review of these meta-analyses concludes that restrictive strategies reduce the need for transfusion, in the UK, without increasing morbidity and mortality [19]. Compliance with WHO paediatric guidelines for rationale use of blood transfusion at Kilifi District Hospital is still sub-optimal. Only 55\% of patients had anaemia or a degree of severity at admission that would qualify for transfusion if the protocol had been adhered to. The rest of the transfusions were received by children who had moderate, mild or no anaemia at admission. Little change in practice was noted throughout the study period. Finally, it was not possible to differentiate exchange transfusion from transfusion for anaemia in the newborn group. This study had design limitations of that did not allow us to track haemoglobin or markers of severity after admission to know what motivated physicians to transfuse these children. Other studies have shown that strict introduction of strict consensus guidelines was insufficient to change prescribing practice, without regular audit and supervision by senior medical staff [20].

\section{Conclusions}

The consequence of a reduction in the number and proportion of cases admitted with falciparum malaria was a decrease in the burden of severe malarial anaemia and a reduction in the demand for paediatric transfusion. Although the reduced malaria burden leads to a welcome reduction in the transfusion requirement the case fatality for those admitted with severe anaemia remains unacceptably high. The most recent systematic reviews $[2,21]$ indicated the need for formal evaluation of the rationale transfusion policy in a controlled trial. Further research to establish best transfusion practice and identify other treatment strategies aimed at reducing in 
hospital mortality is essential in this common paediatric condition in sub-Saharan Africa.

\section{Acknowledgements}

KEMRI-Wellcome Trust Programme received a Wellcome Trust Major Overseas Award to support its core scientific activities (Grant Number 077092). SA is supported by a grant from the Wellcome Trust; 084538. The funders had no role in study design, data collection and analysis, decision to publish, or preparation of the manuscript.

\section{Author details}

'Kenya Medical Research Institute-Wellcome Trust Programme, PO Box 230, Kilifi, Kenya. ${ }^{2}$ Centro de Investigação em Saúde em Angola (CISA), Caxito, Angola. ${ }^{3}$ Department of Paediatrics and Wellcome Trust Centre for Clinical Tropical Medicine, Faculty of Medicine, Imperial College, Norfolk Place, London, W2 IPG, UK.

\section{Authors' contributions}

RP did the primary data analysis and prepare the initial and subsequent versions of the manuscript. SA supervised the data analysis and prepartion of the results table and commented on versions of the manuscripts. KM conceived the study, reviewed the data and draft versions of the manuscript. All authors read and approved the final manuscript.

\section{Competing interests}

The authors declare that they have no competing interests.

Received: 6 August 2010 Accepted: 30 October 2010 Published: 30 October 2010

\section{References}

1. Hospital Care for Children: guidelines for the management of common illnesses with limited resources. Geneva, Switzerland: World Health Organization; 2005.

2. Brabin BJ, Premji Z, Verhoeff F: An analysis of anemia and child mortality. J Nutr 2001, 131(2S-2):636S-645S, discussion 646S-648S.

3. Lackritz EM, Hightower AW, Zucker JR, Ruebush TK, Onudi CO, Steketee RW, Were JB, Patrick E, Campbell CC: Longitudinal evaluation of severely anemic children in Kenya: the effect of transfusion on mortality and hematologic recovery. Aids 1997, 11(12):1487-1494.

4. Global database of blood safety. Summary report 1998-1999. Geneva: World Health Organization, Blood Transfusion Safety, Department of blood transfusion safety and clinical technology; 2000.

5. Calis JC, Phiri KS, Faragher EB, Brabin BJ, Bates I, Cuevas LE, de Haan RJ, Phiri Al, Malange P, Khoka M, et al: Severe anemia in Malawian children. The New England journal of medicine 2008, 358(9):888-899.

6. Nadjm B, Amos B, Mtove G, Ostermann J, Chonya S, Wangai H, Kimera J, Msuya W, Mtei F, Dekker D, et al: WHO guidelines for antimicrobial treatment in children admitted to hospital in an area of intense Plasmodium falciparum transmission: prospective study. BMJ (Clinical research ed) 2010, 340:c1350.

7. Black RE, Cousens S, Johnson HL, Lawn JE, Rudan I, Bassani DG, Jha P, Campbell H, Walker CF, Cibulskis R, et al: Global, regional, and national causes of child mortality in 2008: a systematic analysis. Lancet 2010 375(9730):1969-1987.

8. English M, Ahmed M, Ngando C, Berkley J, Ross A: Blood transfusion for severe anaemia in children in a Kenyan hospital. Lancet 2002, 359(9305):494-495.

9. Lackritz EM, Campbell CC, Ruebush TK, Hightower AW, Wakube W, Steketee RW, Were JB: Effect of blood transfusion on survival among children in a Kenyan hospital. Lancet 1992, 340(8818):524-528.

10. Ghali WA, Palepu A, Paterson WG: Evaluation of red blood cell transfusion practices with the use of preset criteria. Cmaj 1994, 150(9):1449-1454.

11. Akech SO, Hassall O, Pamba A, Idro R, Williams TN, Newton CR, Maitland K: Survival and haematological recovery of children with severe malaria transfused in accordance to WHO guidelines in Kilifi, Kenya. Malar J 2008, 7:256.
12. Lackritz EM, Ruebush TK, Zucker JR, Adungosi JE, Were JB, Campbell CC: Blood transfusion practices and blood-banking services in a Kenyan hospital. Aids 1993, 7(7):995-999.

13. Phiri KS, Calis JC, Faragher B, Nkhoma E, Ng'oma K, Mangochi B, Molyneux ME, van Hensbroek MB: Long term outcome of severe anaemia in Malawian children. PloS one 2008, 3(8):e2903.

14. O'Meara WP, Bejon P, Mwangi TW, Okiro EA, Peshu N, Snow RW, Newton CR, Marsh K: Effect of a fall in malaria transmission on morbidity and mortality in Kilifi, Kenya. Lancet 2008, 372(9649):1555-1562.

15. Gerritsen AA, Kruger P, van der Loeff MF, Grobusch MP: Malaria incidence in Limpopo Province, South Africa, 1998-2007. Malaria journal 2008, 7:162.

16. Lackritz EM, Campbell CC, Ruebush TK, Hightower AW, Wakube W, Steketee RW, Were JB: Effect of blood transfusion on survival among children in a Kenyan hospital. Lancet 1992, 340(8818):524-528.

17. Cheema B, Molyneux EM, Emmanuel JC, M'Baya B, Esan M, Kamwendo H, Kalilani-Phiri L, Boele van Hensbroek M: Development and evaluation of a new paediatric blood transfusion protocol for Africa. Transfus Med 2010, 20(3):140-151.

18. Walker $\mathrm{RH}$ : Mathematical calculations in transfusion medicine. Clin Lab Med 1996, 16(4):895-906

19. Morley SL: Red blood cell transfusions in acute paediatrics. Archives of disease in childhood 2009, 94(3):65-73.

20. Vos J, Gumodoka B, Ng'weshemi JZ, Kigadye FC, Dolmans WM, Borgdorff MW: Are some blood transfusions avoidable? A hospital record analysis in Mwanza Region, Tanzania. Trop Geogr Med 1993, 45(6):301-303.

21. Meremikwu M, Smith HJ: Blood transfusion for treating malarial anaemia. Cochrane database of systematic reviews (Online) 2000, , 2: CD001475.

doi:10.1186/1475-2875-9-307

Cite this article as: Pedro et al:: Changing trends in blood transfusion in children and neonates admitted in Kilifi District Hospital, Kenya. Malaria Journal 2010 9:307.

\section{Submit your next manuscript to BioMed Central and take full advantage of:}

- Convenient online submission

- Thorough peer review

- No space constraints or color figure charges

- Immediate publication on acceptance

- Inclusion in PubMed, CAS, Scopus and Google Scholar

- Research which is freely available for redistribution

Submit your manuscript at www.biomedcentral.com/submit
C Biomed Central 